\title{
Local failure after stereotactic body radiation therapy or wedge resection for colorectal pulmonary metastases
}

David B. Nelson, MD, MSc, ${ }^{\mathrm{a}}$ Nabihah Tayob, PhD, ${ }^{\mathrm{b}}$ Quynh-Nhu Nguyen, MD, ${ }^{\mathrm{c}}$ Jeremy Erasmus, MD, ${ }^{\mathrm{d}}$ Kyle G. Mitchell, MD, ${ }^{\mathrm{a}}$ Wayne L. Hofstetter, MD, ${ }^{\mathrm{a}}$ Boris Sepesi, MD, ${ }^{\mathrm{a}}$ Mara B. Antonoff, MD, ${ }^{\mathrm{a}}$ and Reza J. Mehran, MD

\section{ABSTRACT}

Objective: Several options are available for the local treatment of colorectal pulmonary metastases; however, the efficacy of each treatment has not been well characterized. We compared the risk of local recurrence after wedge resection or stereotactic body radiation therapy for pulmonary metastases of colorectal origin.

Methods: We retrospectively reviewed records of patients treated for pulmonary colorectal metastases with stereotactic body radiation therapy or wedge resection from 2006 to 2016 at a single institution. Local recurrence was defined as an enlarging nodule either adjacent to the staple line or within the radiation field on computed tomography. Matching weights using the propensity score with death as a competing event was used to estimate the risk of local recurrence for each metastatic nodule.

Results: A total of 381 patients underwent 762 wedge resections and 64 courses of stereotactic body radiation therapy for definitive treatment of 826 pulmonary nodules. The risk of local recurrence was increased with stereotactic body radiation therapy (hazard ratio, 3.28; 95\% confidence interval, 1.53-7.04; $P=.002$ ) and larger tumor size (hazard ratio, 1.38 per additional centimeter; $95 \%$ confidence interval, $1.01-1.87 ; P=.042$ ). After reweighting with matching weights, the marginal 2-year risk of local recurrence for each nodule was $14.1 \%$ (95\% confidence interval, 9.8-18.5) after wedge resection and $29.4 \%(95 \%$ confidence interval, 13.8-45.0) after stereotactic body radiation therapy $(P=.023)$.

Conclusions: Pulmonary colorectal metastases treated with stereotactic body radiation therapy have a higher risk of local recurrence than those treated with wedge resection. Stereotactic body radiation therapy should be reserved for patients with comorbidities precluding surgical resection. (J Thorac Cardiovasc Surg 2019;158:1234-41)

From the Departments of ${ }^{\mathrm{a}}$ Thoracic and Cardiovascular Surgery, ${ }^{\mathrm{b}}$ Biostatistics, ${ }^{\mathrm{c}}$ Radiation Oncology, and ${ }^{\mathrm{d}}$ Diagnostic Radiology, The University of Texas MD Anderson Cancer Center, Houston, Tex.

This study was funded by departmental support.

Institutional Review Board Protocol PA17-0119. Approval date: March 20, 2017.

Read at the 98th Annual Meeting of The American Association for Thoracic Surgery, San Diego, California, April 28-May 1, 2018.

Received for publication April 10, 2018; revisions received Jan 19, 2019; accepted for publication Feb 18, 2019; available ahead of print Aug 5, 2019.

Address for reprints: Reza J. Mehran, MD, Department of Thoracic and Cardiovascular Surgery, The University of Texas MD Anderson Cancer Center, 1515 Holcombe Blvd, Unit 1489, Houston, TX 77030 (E-mail: rjmehran@ mdanderson.org).

$0022-5223 / \$ 36.00$

Copyright (c) 2019 by The American Association for Thoracic Surgery

https://doi.org/10.1016/j.jtcvs.2019.02.133

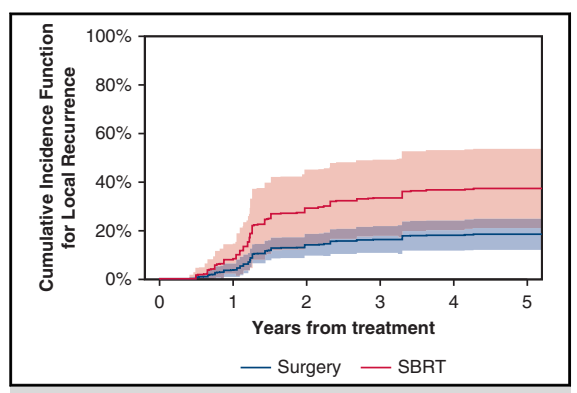

Risk of local recurrence after treatment with SBRT or wedge resection.

Central Message

SBRT is associated with a higher risk of local recurrence than wedge resection for treatment of colorectal pulmonary metastases.

\section{Perspective}

Many therapeutic options are available to treat colorectal pulmonary metastases. However, the risk of local recurrence after SBRT or wedge resection has not been well characterized.

See Commentaries on pages 1242 , 1244, and 1246. 

Abbreviations and Acronyms
CEA $=$ carcinoembryonic antigen
$\mathrm{CI}=$ confidence interval
$\mathrm{CT}=$ computed tomography
$\mathrm{HR}=$ hazard ratio
NSCLC $=$ non-small cell lung cancer
SBRT $=$ stereotactic body radiation therapy

rates higher than $90 \%$ can be achieved for local control of non-small cell lung cancer (NSCLC) while limiting radiotoxicity to nearby lung tissue or organs. ${ }^{5}$ However, radiation-mediated cell death is affected by the oxygen content of the local tissue, and larger tumors and cancers with certain histologic characteristics can show varying degrees of radioresistance. It is still unknown whether the encouraging results seen with SBRT in early-stage NSCLC can be translated to similarly sized lung nodules of different histologies. Pulmonary metastases of a colorectal origin, in particular, have been shown in some reports to be adequately treated with $\mathrm{SBRT}^{6-9}$ and in other reports to be radioresistant. ${ }^{10-17}$

Our purpose in this study was to determine the rate of local recurrence after treatment of pulmonary metastases of a colorectal origin with wedge resection or SBRT. We also sought to identify whether SBRT or other known factors were associated with an increased risk of local recurrence.

\section{MATERIALS AND METHODS \\ Patient Selection}

This study was approved by The University of Texas MD Anderson Cancer Center Institutional Review Board, which waived the requirement for individual informed consent. Prospectively maintained departmental databases in the Department of Radiation Oncology and the Department of Thoracic and Cardiovascular Surgery were queried to identify patients who were treated for pulmonary metastases of a colorectal origin with SBRT or wedge resection from 2006 to 2016 . Exclusion criteria included $\mathrm{R} 1$ or $\mathrm{R} 2$ resection, absence of follow-up imaging, or recurrent treatment (Figure 1 ). Recurrent treatment was defined as the treatment of a nodule that was previously treated with SBRT or wedge resection and had locally recurred.

\section{Study Design}

The primary outcome of interest was the risk of local recurrence per treated metastatic lesion. Each observation in the analysis was a single metastatic colorectal nodule, and the risk of local recurrence was calculated and reported per treated metastatic lesion. To account for the similarity of tumor biology or other factors of multiple treated metastatic lesions within the same patient, statistical methods for clustered data analyses were used. These methods allowed for inclusion of all treated metastatic lesions during the study time period, with the exception of those excluded by the criteria listed.

\section{Covariate Definitions}

Each covariate was determined in the context of each treated metastatic lung nodule. For example, disease-free interval was defined as the time period between the date of primary colorectal resection and the date of diagnosis of the metastatic lung nodule. If the primary tumor was not resected, the date of definitive chemoradiation or local excision was used instead. The number of lung metastases was defined as the number of lung metastases observed on computed tomography (CT) imaging before treatment, whether or not each was treated. Clinical node-positive $(\mathrm{cN}+)$ status was defined as radiographic hilar or mediastinal nodal enlargement greater than $1 \mathrm{~cm}$. Grade and lymphovascular invasion were the highest reported value from the primary tumor or the metastatic lesion. Preoperative carcinoembryonic antigen (CEA) level was defined as the last recorded CEA level within 12 months before treatment. KRAS or TP53 mutations were defined as present or absent.

\section{Follow-up}

Patients were followed with CT or positron emission tomography scans of the chest at 3- to 6-month intervals. Adherence to surveillance was not available. Local recurrence was defined radiographically as an enlarging nodule adjacent to the staple line or within the $50 \%$ isodose line on CT imaging at least 6 months after treatment. All recurrences after treatment with SBRT were required to be within the $50 \%$ isodose line and confirmed by a radiologist and radiation oncologist.

\section{Statistical Methods}

Differences between groups on patient-specific characteristics were calculated using chi-square or Fisher exact tests, where appropriate. Differences between groups regarding nodule characteristics were calculated using generalized linear models with robust variance to account for clustering within patients.

Competing-risk analyses were used for all reported time to event outcomes. We considered death within 2 years of last CT imaging as a competing event, but death more than 2 years after last CT imaging was considered lost to follow-up at last CT image. In the absence of local recurrence or death, observations were censored on the date of last CT imaging. We explored an alternative analysis with death at any point as a competing event without a change in results. A semiparametric random effects model for clustered competing risks data, implemented in the timereg $\mathrm{R}$ package, was used to estimate the subdistribution hazard ratio (HR) of each factor toward the risk of local recurrence in the unweighted cohort. $^{18,19}$

To reduce the impact of treatment selection bias, a matching weight analysis using the propensity score was used. ${ }^{20,21}$ The data were reweighted using the matching weights, the competing risks models were fit in the reweighted data, and a bootstrap procedure was used to estimate the variance of model parameters. A generalized linear model with a logit link, unstructured correlation structure, and robust variance estimate was used to estimate the propensity that an individual nodule would be treated with SBRT or surgery. The propensity score was estimated using the following variables: tumor size, disease-free interval, grade, lymphovascular invasion, perineural invasion, preoperative CEA level, number of lung metastases, and KRAS mutational status. The propensity score variables were selected a priori on the basis of perceived likelihood of influencing local recurrence or treatment selection. Further details regarding the selection of the propensity score model and covariate balance before and after applying the matching weights are provided in Appendix E1. In the case of missing data, such as KRAS status, presence of lymphovascular invasion, perineural invasion, or CEA level, a missing dummy variable was created to prevent cases from dropping out of the model (Appendix E2). All statistical analyses were performed using $\mathrm{R}$ version 3.3.2.

\section{RESULTS}

\section{Patient and Tumor Characteristics}

A total of 381 patients met the inclusion criteria. These patients underwent 762 wedge resections and 64 courses of SBRT for definitive therapy of 826 pulmonary nodules. 


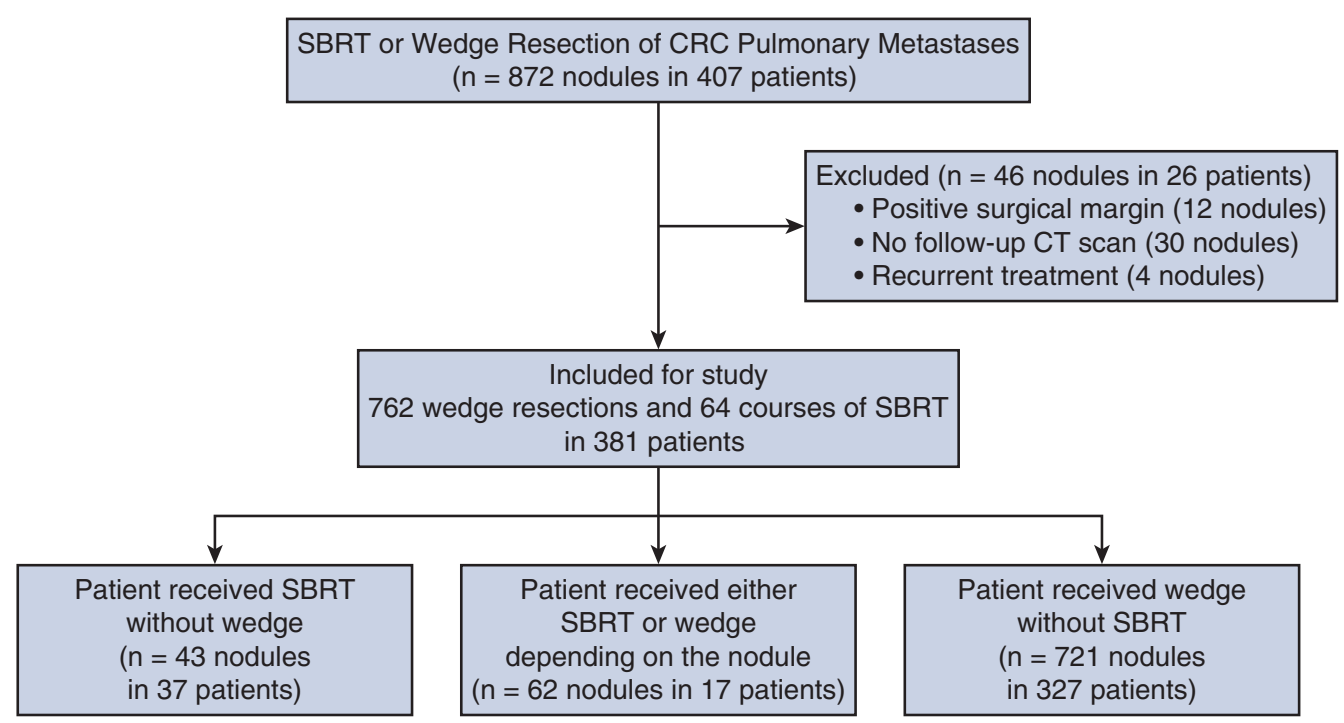

FIGURE 1. Flowchart showing SBRT or wedge resection of colorectal pulmonary metastases at MD Anderson Cancer Center from 2006 to 2016. $S B R T$, Stereotactic body radiation therapy; $C R C$, colorectal carcinoma; $C T$, computed tomography.

SBRT dose fractionation was as follows: (4) 54 cGy in 3 fractions; (49) 50 cGy in 4 fractions; (1) 50 cGy in 5 fractions, (1) $50 \mathrm{cGy}$ in 10 fractions; (9) $70 \mathrm{cGy}$ in 10 fractions. Median follow-up to last known contact was 4.4 years. Median follow-up to last recorded CT imaging was 1.8 years after SBRT and 2.6 years after wedge resection. Patients who underwent wedge resection were younger (mean age, 57 vs 62 years) and had a higher rate of lymphovascular invasion within the primary tumor $(56 \%$ vs $30 \%)$. However, we found no significant differences in tumor grade, presence of perineural invasion, or mutational status between the wedge resection and SBRT groups (Table 1).

Additionally, at the time of resection, patients who underwent wedge resection had more lung nodules than patients who underwent SBRT (median, 3.0 vs 1.5; $P<.001)$. Surgical patients also had a shorter disease-free interval (median, 1.3 vs 2.5 years; $P<.001$ ) and smaller tumors (median, 1.0 vs $1.3 \mathrm{~cm}$; $P=.003)$ and more often underwent adjuvant chemotherapy ( $32 \%$ vs $16 \% ; P=.017)$. There were no differences in preoperative CEA levels, rates of response to induction chemotherapy if given, $\mathrm{cN}+$ status, and history of extrathoracic metastatic disease before treatment (Table 2).

\section{Factors Associated With Local Recurrence}

Multivariable analysis with death as a competing event using the unweighted cohort was used to identify risk factors for local recurrence. Larger tumor size (HR, 1.38 per additional centimeter; $P=.042$ ) and treatment with SBRT (HR, 3.28; $P=.002$ ) were independently associated with an increased risk of local recurrence. The other analyzed factors, including KRAS mutational status, disease-free interval, lymphovascular invasion, and response to preprocedure chemotherapy, were not associated with the risk of local recurrence (Table 3).

\section{Rate of Local Recurrence After Wedge Resection or Stereotactic Body Radiation Therapy Using Matching Weights}

Matching weights using the propensity score were applied for subsequent analysis. After weighting, pretreatment differences between those treated with SBRT or wedge resection were no longer statistically different (Table 2 and Appendix E1).

After applying matching weights, the risk of local treatment failure within 2 years for each nodule was $14.1 \%(95 \%$ confidence interval [CI], 9.8-18.5) after wedge resection and $29.4 \%$ (95\% CI, 13.8-45.0) after SBRT. The risk of local treatment failure within 5 years was $18.4 \%$ after wedge resection $(95 \% \mathrm{CI}, 12.1-24.7)$ and $37.3 \%$ after SBRT (95\% CI, 21.1-53.6).

\section{Exploratory Sensitivity and Subgroup Analysis Using Matching Weights}

To investigate whether rates of local control with SBRT are more favorable in a select population, we performed an exploratory subgroup analysis. In the subgroup of tumors smaller than $3 \mathrm{~cm}$, arguably a population that SBRT should be restricted to $(n=809)$, local recurrence was largely unchanged and within 2 years was $26.1 \%(95 \% \mathrm{CI}$, 12.1-40.3) and within 5 years was $34.4 \%(95 \% \mathrm{CI}$, 19.1-49.8) after SBRT, and $14.0 \%(95 \%$ CI, 9.9-18.2) 
TABLE 1. Demographic and clinical characteristics of 381 patients with colorectal pulmonary metastases*

\begin{tabular}{|c|c|c|c|c|}
\hline Characteristic & SBRT only $\dagger(\mathbf{n}=\mathbf{3 7})$ & Wedge only $\dagger(n=327)$ & SBRT and wedge $(N=17)$ & $P$ value \\
\hline Age at first treatment (y) & $62 \pm 10$ & $57 \pm 12$ & $55 \pm 12$ & .021 \\
\hline $\begin{array}{l}\text { Sex } \\
\qquad \text { Male } \\
\text { Female }\end{array}$ & $\begin{array}{l}23(62 \%) \\
14(38 \%)\end{array}$ & $\begin{array}{l}188(57 \%) \\
139(43 \%)\end{array}$ & $\begin{array}{r}11(65 \%) \\
6(35 \%)\end{array}$ & .779 \\
\hline $\begin{array}{l}\text { Primary tumor location } \\
\text { Colon } \\
\text { Rectum }\end{array}$ & $\begin{array}{l}21(57 \%) \\
16(43 \%)\end{array}$ & $\begin{array}{l}182(56 \%) \\
145(44 \%)\end{array}$ & $\begin{array}{r}10(59 \%) \\
7(41 \%)\end{array}$ & 1.00 \\
\hline $\begin{array}{l}\text { Primary tumor grade } \\
\text { Well differentiated } \\
\text { Moderately differentiated } \\
\text { Poorly differentiated }\end{array}$ & $\begin{array}{c}0 \\
33(89 \%) \\
4(11 \%)\end{array}$ & $\begin{array}{c}5(2 \%) \\
285(87 \%) \\
37(11 \%)\end{array}$ & $\begin{array}{c}1(6 \%) \\
16(94 \%) \\
0(0 \%)\end{array}$ & .311 \\
\hline $\begin{array}{l}\text { Primary tumor lymphovascular invasion } \\
\text { Absent } \\
\text { Present } \\
\text { Not reported }\end{array}$ & $\begin{array}{r}20(54 \%) \\
11(30 \%) \\
6(16 \%)\end{array}$ & $\begin{array}{r}96(28 \%) \\
192(56 \%) \\
55(16 \%)\end{array}$ & $\begin{array}{c}3(18 \%) \\
13(76 \%) \\
1(6 \%)\end{array}$ & .006 \\
\hline $\begin{array}{l}\text { Primary tumor perineural invasion } \\
\text { Absent } \\
\text { Present } \\
\text { Not reported }\end{array}$ & $\begin{array}{l}13(35 \%) \\
13(35 \%) \\
11(30 \%)\end{array}$ & $\begin{array}{r}93(27 \%) \\
108(31 \%) \\
142(41 \%)\end{array}$ & $\begin{array}{l}5(29 \%) \\
4(24 \%) \\
8(47 \%)\end{array}$ & .612 \\
\hline $\begin{array}{l}\text { Primary tumor KRAS mutation } \\
\text { Absent } \\
\text { Present } \\
\text { Not reported }\end{array}$ & $\begin{array}{l}11(30 \%) \\
16(43 \%) \\
10(27 \%)\end{array}$ & $\begin{array}{r}124(38 \%) \\
130(40 \%) \\
73(22 \%)\end{array}$ & $\begin{array}{l}9(53 \%) \\
6(35 \%) \\
2(12 \%)\end{array}$ & .568 \\
\hline $\begin{array}{l}\text { Primary tumor TP53 mutation } \\
\text { Absent } \\
\text { Present } \\
\text { Not reported }\end{array}$ & $\begin{array}{r}5(14 \%) \\
6(16 \%) \\
26(70 \%)\end{array}$ & $\begin{array}{r}35(11 \%) \\
87(27 \%) \\
205(63 \%)\end{array}$ & $\begin{array}{c}0(0 \%) \\
6(35 \%) \\
11(65 \%)\end{array}$ & .361 \\
\hline
\end{tabular}

SBRT, Stereotactic body radiation therapy. *Represents patient-level characteristics. †Reported as mean \pm standard deviation or $\mathrm{N}(\%)$.

and $19.0 \%(95 \% \mathrm{CI}, 12.9-25.2)$ after wedge resection, respectively. The risk of local recurrence after SBRT compared with wedge resection was also increased to a similar magnitude (HR, 2.00; $P=.05)$. An additional exploratory analysis was performed in which the 12 resected nodules with a positive surgical margin were considered to be local recurrences. After these changes, the risk of local recurrence within 2 years after wedge resection was marginally increased to $15.2 \%(95 \% \mathrm{CI}$, 10.4-20.0), without a change in statistical significance. We were unable to find a subgroup of SBRT dose or fractionation with improved efficacy (Figure 2 and Video 1).

\section{DISCUSSION}

SBRT is associated with a higher risk of local recurrence than wedge resection when used to treat colorectal pulmonary metastases. Additional risk factors for local recurrence include larger tumor size. However, other tested factors, including KRAS mutational status, were not associated with the risk of local recurrence.

SBRT has been shown to be an effective therapy for NSCLC and has emerged as the de facto therapy for patients who are not surgical candidates. ${ }^{1-5}$ As a result of these favorable results for NSCLC, use of SBRT has been increasing for pulmonary metastases. A recent review on the use of SBRT for oligometastases from colorectal cancer highlighted favorable results for both liver and pulmonary metastases, with quoted local recurrence rates less than $20 \%$ and stated to be overall comparable to surgical resection. ${ }^{22}$ However, much of the research supporting the use of SBRT for colorectal pulmonary metastases combined results from multiple histologies and failed to stratify by histologic subtype. ${ }^{6-8}$ In studies that analyzed metastases of colorectal histology alone, evidence of radioresistance emerged. $^{10-17}$ Part of this confusion may arise because although there is little evidence that surgery and thermal ablation differ in their ability to achieve local control depending on the cancer histology, there is ample evidence that tumor histology and radiosensitivity interact. ${ }^{23}$ Dose escalation may be required for colorectal pulmonary metastases, and investigations are under way to determine whether higher doses improve local control rates. ${ }^{24}$

Management of pulmonary metastases is complex and often requires multidisciplinary coordination. The decision 
TABLE 2. Characteristics of metastatic lung nodules at treatment*

\begin{tabular}{|c|c|c|c|c|c|c|}
\hline \multirow[b]{2}{*}{ Characteristic } & \multicolumn{3}{|c|}{ Unadjusted data } & \multicolumn{3}{|c|}{ Data adjusted by matching weight } \\
\hline & $\overline{\text { SBRT } \dagger(\mathbf{n}=\mathbf{6 4})}$ & Wedge $\nmid(n=762)$ & $P$ value & SBRT & Wedge & $P$ value \\
\hline No. of lung nodules present & $1.5(1-2)$ & $3.0(2-5)$ & $<.001$ & 2.0 & 2.0 & .818 \\
\hline Clinical node-positive status (hilar/mediastinal) & $5(8 \%)$ & $44(6 \%)$ & .539 & $8 \%$ & $7 \%$ & .901 \\
\hline History of extrathoracic disease & $26(41 \%)$ & $394(52 \%)$ & .164 & $40 \%$ & $44 \%$ & .642 \\
\hline Pathologic confirmation & $22(34 \%)$ & N/A (all) & & & & \\
\hline Induction chemotherapy response & & & .892 & & & .464 \\
\hline Not given & $37(58 \%)$ & $417(55 \%)$ & & $58 \%$ & $62 \%$ & \\
\hline Response & $8(13 \%)$ & $74(10 \%)$ & & $13 \%$ & $10 \%$ & \\
\hline No change & $7(11 \%)$ & $123(16 \%)$ & & $11 \%$ & $15 \%$ & \\
\hline Progression & $12(19 \%)$ & $148(19 \%)$ & & $19 \%$ & $13 \%$ & \\
\hline Disease-free interval (y) & $2.5(1.1-4.9)$ & $1.3(0.2-2.6)$ & $<.001$ & 2.5 & 2.5 & .962 \\
\hline Tumor size $(\mathrm{cm})$ & $1.3(0.9-1.7)$ & $1.0(0.6-1.4)$ & .003 & 1.3 & 1.2 & .744 \\
\hline Preoperative CEA level (ng/mL) & $2.6(1.6-4.2)$ & $2.1(1.2-4.0)$ & .341 & 2.4 & 2.2 & .805 \\
\hline Adjuvant chemotherapy & $10(16 \%)$ & $240(31 \%)$ & .017 & $15 \%$ & $36 \%$ & .004 \\
\hline
\end{tabular}

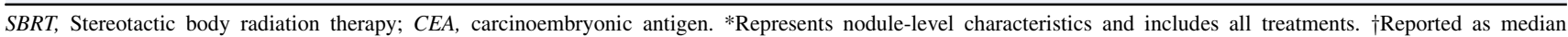
(interquartile range) or $\mathrm{N}(\%)$ unless otherwise specified.

to treat a patient with one local strategy or another requires balancing the perceived risks of new pulmonary metastases, systemic failure, the extent of resection or radiation fields that would be required, the expected life span of the patient, and other factors. Pulmonary metastases of a colorectal origin, in particular, may be favorably treated with SBRT because of the technique's relative ease, ability to preserve

TABLE 3. Multivariable factors associated with the risk of local recurrence, unweighted cohort

\begin{tabular}{|c|c|c|}
\hline Factor & HR $(95 \%$ CI $)$ & $P$ value \\
\hline SBRT & $3.28(1.53-7.04)$ & .002 \\
\hline Tumor size (per cm) & $1.38(1.01-1.87)$ & .042 \\
\hline Disease-free interval (per year) & $0.89(0.77-1.03)$ & .110 \\
\hline \multicolumn{3}{|l|}{ KRAS } \\
\hline Wild-type (reference) & - & - \\
\hline Mutant & $0.92(0.54-1.57)$ & .756 \\
\hline Missing & $0.16(0.04-0.64)$ & .010 \\
\hline \multicolumn{3}{|l|}{ Differentiation } \\
\hline Well-moderate (reference) & - & - \\
\hline Poor & $1.76(0.90-3.46)$ & .099 \\
\hline \multicolumn{3}{|l|}{ Lymphovascular invasion } \\
\hline Absent (reference) & - & - \\
\hline Present & $0.83(0.45-1.51)$ & .534 \\
\hline Missing & $0.92(0.40-2.13)$ & .852 \\
\hline \multicolumn{3}{|l|}{ Response to chemotherapy } \\
\hline Not given (reference) & - & - \\
\hline Response & $0.80(0.31-2.03)$ & .632 \\
\hline No change & $1.06(0.49-2.32)$ & .879 \\
\hline Progression & $0.50(0.24-1.06)$ & .069 \\
\hline
\end{tabular}

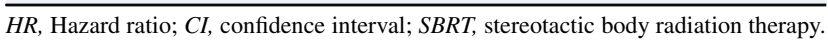

the parenchyma, and favorable morbidity and mortality rates relative to surgery. One valid criticism of studying local recurrence as a primary end point is that it is still unknown how local recurrence may affect long-term survival or other important end points, especially because our cohort consisted entirely of patients with stage IV cancer. To mitigate the effect of these issues, many studies comparing SBRT and surgery focus on overall survival or recurrence-free survival. ${ }^{25,26}$ However, in the presence of strong treatment biases like those that often occur between SBRT and surgery, even with an adequately specified propensity score, the propensity matching or inverse probability of treatment weighting model may fail

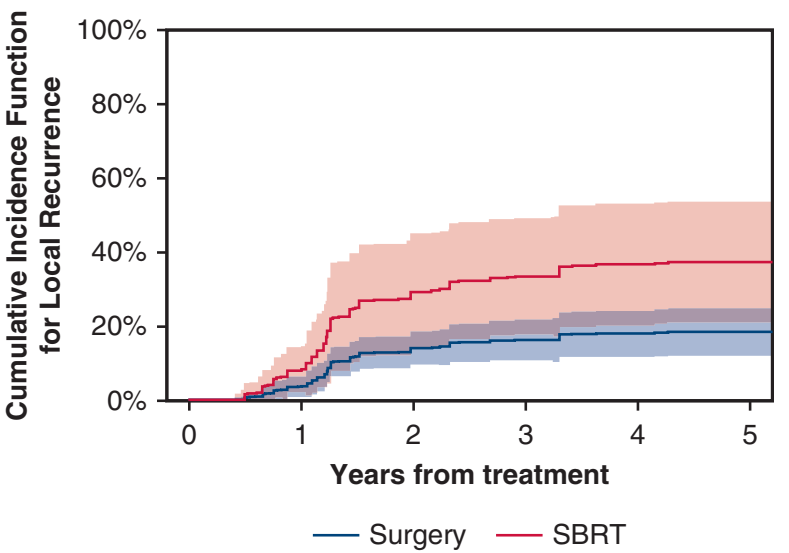

FIGURE 2. Cumulative incidence function indicating risk of local recurrence is higher with SBRT compared with wedge resection. Results modeled with death as a competing risk using matching weights. $S B R T$, Stereotactic body radiation therapy. 


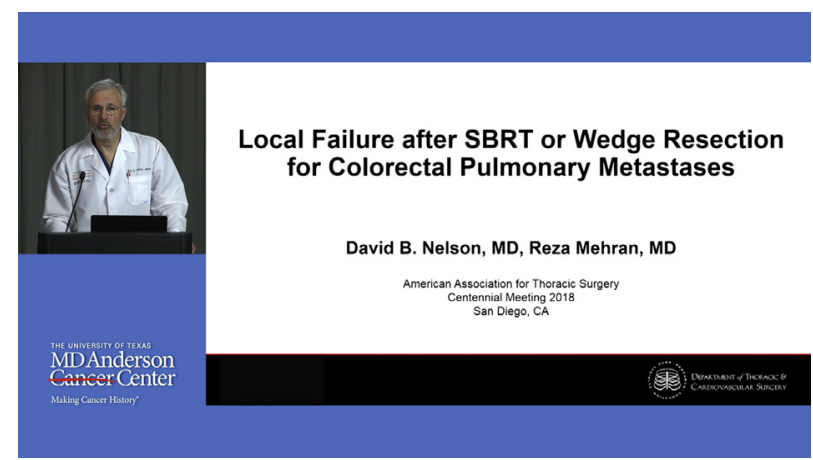

VIDEO 1. Local failure after treatment of local treatment of metastases from a primary colorectal carcinoma. Video available at: https://www. jtcvs.org/article/S0022-5223(19)30972-9/fulltext.

to achieve balance. ${ }^{27}$ The argument is that it may be difficult to find overlap among patients treated with SBRT or surgery when there are strong biases pushing patients toward one therapy or another. Although we do not think that we entirely escaped this limitation, we did hope to mitigate its effects by focusing on local recurrence.

\section{Study Limitations}

There are several limitations inherent to this analysis. First, we defined local recurrence radiographically. This was not a prospective study, and many patients never underwent a biopsy to obtain histologic evidence of recurrence. However, suspicious radiographic findings were confirmed by a radiation oncologist and a radiologist to show radiographic features consistent with local recurrence. All local recurrences were further confirmed to be within the $50 \%$ isodose line. Second, we defined local failure as a recurrence happening at any point in time. Of note, several recurrences after SBRT occurred late, after the patient had already experienced systemic failure. Thus, one could argue that at least several of our local recurrences were clinically irrelevant. Again, this highlights the importance of overall survival or recurrence-free survival analysis. Third, there may also be a risk of residual confounding in this retrospective study, although we used a robust propensity score model and our treatment effect size was large. Last, the expertise of providers at our quaternary cancer center may not be generalizable to other institutions.

\section{CONCLUSIONS}

We observed that an increased risk of local failure was found among colorectal pulmonary metastases that were treated with SBRT compared with wedge resection. In addition, in light of our evidence that colorectal pulmonary metastases harbor radioresistance, future studies should stratify results by histologic subtype. Future research will be required to identify favorable subtypes that may be effectively treated with SBRT.

\section{Webcast}

You can watch a Webcast of this AATS meeting presentation by going to: https://aats.blob.core.windows.net/media/18Apr 29/25ABC\%20General\%20Thoracic\%20SS/S53/S53_2_ webcast_033610441.mp4.

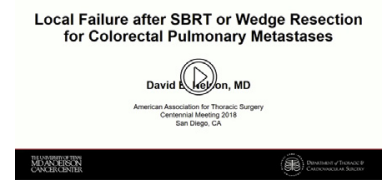

\section{Conflict of Interest Statement}

Authors have nothing to disclose with regard to commercial support.

\section{References}

1. Chang JY, Senan S, Paul MA, Mehran RJ, Louie AV, Balter P, et al. Stereotactic ablative radiotherapy versus lobectomy for operable stage I non-small-cell lung cancer: a pooled analysis of two randomised trials. Lancet Oncol. 2015;16:630-7.

2. Paul S, Lee PC, Mao J, Isaacs AJ, Sedrakyan A. Long term survival with stereotactic ablative radiotherapy (SABR) versus thoracoscopic sublobar lung resection in elderly people: national population based study with propensity matched comparative analysis. BMJ. 2016;354:13570.

3. Timmerman R, Paulus R, Galvin J, Michalski J, Straube W, Bradley J, et al. Stereotactic body radiation therapy for inoperable early stage lung cancer. JAMA 2010;303:1070-6.

4. Crabtree TD, Denlinger CE, Meyers BF, El Naqa I, Zoole J, Krupnick A, et al. Stereotactic body radiation therapy versus surgical resection for stage I nonsmall cell lung cancer. J Thorac Cardiovasc Surg. 2010;140:377-86.

5. Solda F, Lodge M, Ashley S, Whitington A, Goldstraw P, Brada M. Stereotactic radiotherapy $(\mathrm{SABR})$ for the treatment of primary non-small cell lung cancer; systematic review and comparison with a surgical cohort. Radiother Oncol. 2013;109:1-7.

6. Navarria P, Ascolese AM, Tomatis S, Cozzi L, De Rose F, Mancosu P, et al. Stereotactic body radiotherapy (SBRT) in lung oligometastatic patients: role of local treatments. Radiat Oncol. 2014;9:91.

7. Takeda A, Sanuki N, Tsurugai Y, Oku Y, Aoki Y. Stereotactic body radiotherapy for patients with oligometastases from colorectal cancer: risk-adapted dose prescription with a maximum dose of $83-100$ Gy in five fractions. J Radiat Res. 2016;57:400-5.

8. Rusthoven KE, Kavanagh BD, Burri SH, Chen C, Cardenes H, Chidel MA, et al. Multi-institutional phase I/II trial of stereotactic body radiation therapy for lung metastases. J Clin Oncol. 2009;27:1579-84.

9. Jung J, Song SY, Kim JH, Yu CS, Kim JC, Kim TW, et al. Clinical efficacy of stereotactic ablative radiotherapy for lung metastases arising from colorectal cancer. Radiat Oncol. 2015;10:238.

10. Binkley MS, Trakul N, Jacobs LR, von Eyben R, Le QT, Maxim PG, et al. Colorectal histology is associated with an increased risk of local failure in lung metastases treated with stereotactic ablative radiation therapy. Int J Radiat Oncol Biol Phys. 2015;92:1044-52.

11. Milano MT, Katz AW, Schell MC, Philip A, Okunieff P. Descriptive analysis of oligometastatic lesions treated with curative-intent stereotactic body radiotherapy. Int J Radiat Oncol Biol Phys. 2008;72:1516-22.

12. Takeda A, Kunieda E, Ohashi T, Aoki Y, Koike N, Takeda T. Stereotactic body radiotherapy (SBRT) for oligometastatic lung tumors from colorectal cancer and other primary cancers in comparison with primary lung cancer. Radiother Oncol. 2011;101:255-9.

13. Hamamoto Y, Kataoka M, Yamashita M, Nogami N, Sugawara Y, Kozuki T, et al Factors affecting the local control of stereotactic body radiotherapy for lung tumors including primary lung cancer and metastatic lung tumors. Jpn J Radiol. 2012;30:430-4. 
14. Thibault I, Poon I, Yeung L, Erler D, Kim A, Keller B, et al. Predictive factors for local control in primary and metastatic lung tumours after four to five fraction stereotactic ablative body radiotherapy: a single institution's comprehensive experience. Clin Oncol (R Coll Radiol). 2014;26:713-9.

15. Yamamoto T, Jingu K, Shirata Y, Koto M, Matsushita H, Sugawara T, et al. Outcomes after stereotactic body radiotherapy for lung tumors, with emphasis on comparison of primary lung cancer and metastatic lung tumors. BMC Cancer. 2014; $14: 464$.

16. Franceschini D, Cozzi L, De Rose F, Navarria P, Franzese C, Comito T, et al. Role of stereotactic body radiation therapy for lung metastases from radio-resistant primary tumours. J Cancer Res Clin Oncol. 2017;143:1293-9.

17. Kim MS, Yoo SY, Cho CK, Yoo HJ, Choi CW, Seo YS, et al. Stereotactic body radiation therapy using three fractions for isolated lung recurrence from colorectal cancer. Oncology. 2009;76:212-9.

18. Scheike TH, Sun Y, Zhang MJ, Jensen TK. A semiparametric random effects model for multivariate competing risks data. Biometrika. 2010;97:133-45.

19. Scheike TH, Zhang MJ. Analyzing competing risk data using the R timereg Package. J Stat Softw. 2011;38.

20. Li L, Greene T. A weighting analogue to pair matching in propensity score analysis. Int J Biostat. 2013;9:215-34.

21. Austin PC, Stuart EA. Moving towards best practice when using inverse probability of treatment weighting (IPTW) using the propensity score to estimate causal treatment effects in observational studies. Stat Med. 2015;34:3661-79.

22. Takeda A, Sanuki N, Kunieda E. Role of stereotactic body radiotherapy for oligometastasis from colorectal cancer. World J Gastroenterol. 2014;20:4220-9.

23. Kingham TP, Tanoue M, Eaton A, Rocha FG, Do R, Allen P, et al. Patterns of recurrence after ablation of colorectal cancer liver metastases. Ann Surg Oncol. 2012;19:834-41.

24. Jingu K, Matsuo Y, Onishi H, Yamamoto T, Aoki M, Murakami Y, et al. Dose escalation improves outcome in stereotactic body radiotherapy for pulmonary oligometastases from colorectal cancer. Anticancer Res. 2017;37:2709-13.

25. Lodeweges JE, Klinkenberg TJ, Ubbels JF, Groen HJM, Langendijk JA, Widder J. Long-term outcome of surgery or stereotactic radiotherapy for lung oligometastases. J Thorac Oncol. 2017;12:1442-5.

26. Widder J, Klinkenberg TJ, Ubbels JF, Wiegman EM, Groen HJM, Langendijk JA. Pulmonary oligometastases: metastasectomy or stereotactic ablative radiotherapy? Radiother Oncol. 2013;107:409-13.

27. Austin PC, Stuart EA. The performance of inverse probability of treatment weighting and full matching on the propensity score in the presence of model misspecification when estimating the effect of treatment on survival outcomes. Stat Methods Med Res. 2017;26:1654-70.

Key Words: colorectal carcinoma, metastasis, SBRT, lung resection

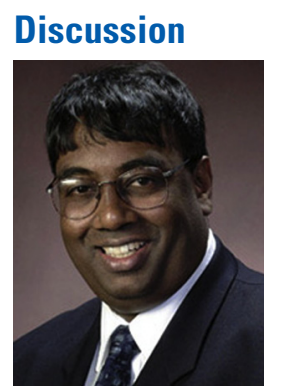

Dr H. Fernando (Falls Church, Va). I congratulate Dr Nelson and all the co-authors at MD Anderson for this presentation, and it is important as we try to juggle the appropriate treatment options that we have available to us. I agree with your conclusion and recommendations that SBRT should be reserved with patients with comorbidities precluding surgery, but I am going to play the devil's advocate here and pretend I am a radiation oncologist and argue with you.

So one of the things was that in your exclusion criteria you excluded patients who had an R1 or R2 resection, so you are kind of unfairly biasing against SBRT, because if you are going with an intent-to-treat analysis, you should be including those patients.

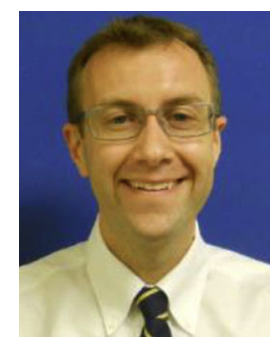

Dr David B. Nelson (Houston, Tex). That's a great point. We initially excluded patients with an R1/R2 margin because they often had a subsequent procedure to address the positive margin, at least in most cases, and so most of them didn't have a later recurrence. One of the coauthors suggested that we count them as a recurrence on day 0 , which I think is another valid approach. It's only 11 of 762 , which is $1-1 / 2 \%$, and it's probably not going to change results meaningfully, but that's another approach.

Dr Fernando. In the article, you talked about having seen positive nodes, which you didn't put into your propensity analysis, but also if you see clinically what might be positive nodes, how do you manage those patients if you are going to do surgery or SBRT?

Dr Nelson. Clinically positive nodes were defined radiographically by size criteria. We did not have pathologic nodal data available on all patients. In terms of how they are managed, because we are looking at local recurrence, if they had a resection and there was a negative margin, we included it for the study. Not all the patients who we included were rendered with no evidence of disease after their treatment. Some of them had a resection to obtain tissue to guide systemic therapy and so forth. In several of those cases, it was systemic therapy.

Dr Fernando. Do you think those patients should be staged beforehand, especially before SBRT, with an endobronchial ultrasound or a mediastinoscopy?

Dr Nelson. I think excluding $\mathrm{N}$ positive is important because it has been known to be a poor prognostic indicator.

Dr Fernando. Now, you already said that local recurrence was defined radiologically, and so we don't truly know if it was a local recurrence or whether this was just progressive scarring, and you also didn't have the benefit of biopsies. So I think a more important analysis would be survival and to present what the survival differences were between the 2 groups.

Dr Nelson. That's a great question. In terms of the recurrences, we waited at least 6 months for all of them to exclude that this was an evolving radiation scar. Our recurrence rate is also consistent with that published in other series. There is a recent article by Dr Binkley at Stanford that showed that the local recurrence rate for colorectal metastases within 2 years was $42 \%$, whereas for their entire cohort including other histologies the local recurrence rate within 2 years was $16 \%$. These cases were also confirmed by a radiation oncologist and diagnostic radiologist. But you are right, without tissue you never really know.

In terms of overall survival, it wasn't the objective of our study evaluate overall survival. We likely have to change our selection criteria to truly get a good, proper survival 
analysis, such as excluding patients who had radiographic nodal enlargement pretreatment. However, the surgical patients did live longer. Median survival was 6 years after a wedge resection and 3.3 years after SBRT.

Dr Fernando. How did you select patients for SBRT or surgery in your institution?

Dr Nelson. Patients are selected for SBRT or surgery in a multidisciplinary fashion, and there is no set treatment algorithm for them.

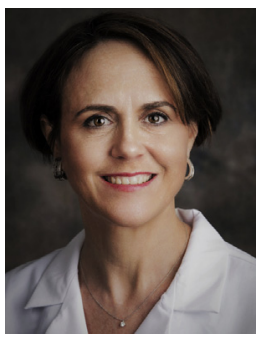

Dr J. Donington (Chicago, Ill). I don't see any radiation information in the abstract. Do you have information on central versus peripheral tumor location for recurrences after radiation? Do you have information on the biological equivalent dose and the number of fractions and did that correlate with recurrence?

Dr Nelson. We did try to find subgroups that would be more likely to have recurrence. All patients in this study received at least $50 \mathrm{~Gy}$. We could not identify any association between the number of fractions and local recurrence, or another association such as temporal trends or anything like that.

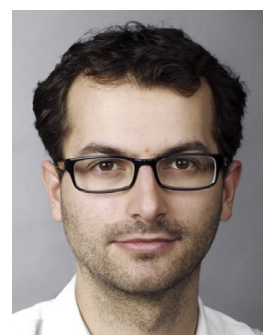

Dr K. Hoetzenecker (Vienna, Austria). When you talk about local recurrence, it is important to look at resection margins. What was the safety margin of your surgical group and what was the safety margin of your SBRT group in terms of radiation field? We know that colorectal cancer metastases like to form micrometastases directly neighboring the main nodule.

Dr Nelson. For the safety margin for the surgical group, that's actually going to be presented tomorrow as another abstract, so you will have to wait for that answer. For the SBRT group, we typically have at least a 5-mm margin, from my understanding.

Dr Hoetzenecker. In my opinion, this should be larger, more like $2 \mathrm{~cm}$. 


\section{APPENDIX E1. PROPENSITY SCORE DEVELOPMENT REPORT \\ Propensity Score Model}

The propensity score models the probability that a nodule is treated with SBRT (rather than surgery). We fit a generalized linear model with a logit link and an unstructured correlation structure.

The following variables were initially selected to be included in the propensity score model as they influence treatment selection (SBRT or surgery) or are prognostically important (associated with a risk of local recurrence).

Disease-free interval

Primary tumor grade

Lymphovascular invasion

Perineural invasion

Preoperative CEA level

Tumor size

KRAS mutation

Number of lung metastases

Other clinical variables available in the analysis dataset but were initially considered to be less important factors affecting treatment selection or prognostically important. We evaluate whether these variables should be included.

Age

Clinical node-positive status

History of extrathoracic disease

Response to induction chemotherapy

The following variables are most important to induce balance because they are considered prognostically important.

Number of lung metastases

Disease-free interval

Lymphovascular invasion

Tumor size

Perineural invasion

Preoperative CEA level

KRAS mutation

Primary tumor grade

We consider 6 possible propensity models

- Linear selected: preselected variables, continuous variables enter linearly into the model except number of lung metastases (categorized into $\geq 2$ vs $\leq 1$, model unable to converge when included as a linear continuous variable)

- Linear selected v2: preselected variables, continuous variables enter linearly into the model except number of lung metastases (restricted cubic spline with 5 knots)

- Nonlinear selected: preselected variables, continuous variables enter nonlinearly into the model using restricted cubic splines with 3 or 5 knots.

- Linear full: all variables, continuous variables enter linearly into the model except number of lung metastases (categorized into $\geq 2$ vs $\leq 1$, model unable to converge when included as a linear continuous variable)

- Linear full v2: all variables, continuous variables enter linearly into the model except number of lung metastases (restricted cubic spline with 5 knots)

- Nonlinear all: all variables, continuous variables enter nonlinearly into the model using restricted cubic splines with 3 or 5 knots.

The variables are included in the model in the following form:

\section{Continuous variables:}

Tumor size

Preoperative CEA level (including an indicator variable for unknown preoperative CEA level)

Number of lung metastases (either categorized into $\geq 2$ vs $\leq 1$ or a restricted cubic spline with 5 knots)

Age

Categoric variables:

Primary tumor grade

- Poorly differentiated

- Reference category: well-moderately differentiated

Lymphovascular invasion

- Absent

- Not reported

- Reference category: present

Perineural invasion

- Absent

- Present

- Reference category: not reported

KRAS mutation

- Absent

- Not reported

- Reference category: present

Clinical node-positive status

- Yes

- Reference category: no

History of extrathoracic disease

- Yes

- Reference category: no

Response to induction chemotherapy

- Response or no change

- Progression

- Reference category: not given

\section{Weighting Analysis}

We consider 2 possible weighting approaches. The first is the stabilized inverse probability of treatment weights (Cole and Hernan, 2008) and the second is the pair matching weighting analogue (Li and Greene, 2013). 
Let $e=\operatorname{Pr}(Z=1 \mid X)$ be the probability of a nodule being treated with SBRT conditional on the observed baseline covariates, where $Z=1$ if the nodule is treated with SBRT and $Z=0$ if the nodule is treated with surgery.

The stabilized weights are

$$
w_{\text {stable }}=\frac{Z \operatorname{Pr}(Z=1)}{e}+\frac{(1-Z) \operatorname{Pr}(Z=0)}{1-e}
$$

The matching weights are

$$
w_{\text {match }}=\frac{\min (1-e, e)}{Z e+(1-Z)(1-e)}
$$

We show the distributions of the propensity weights in the surgery and SBRT treatment groups, respectively.
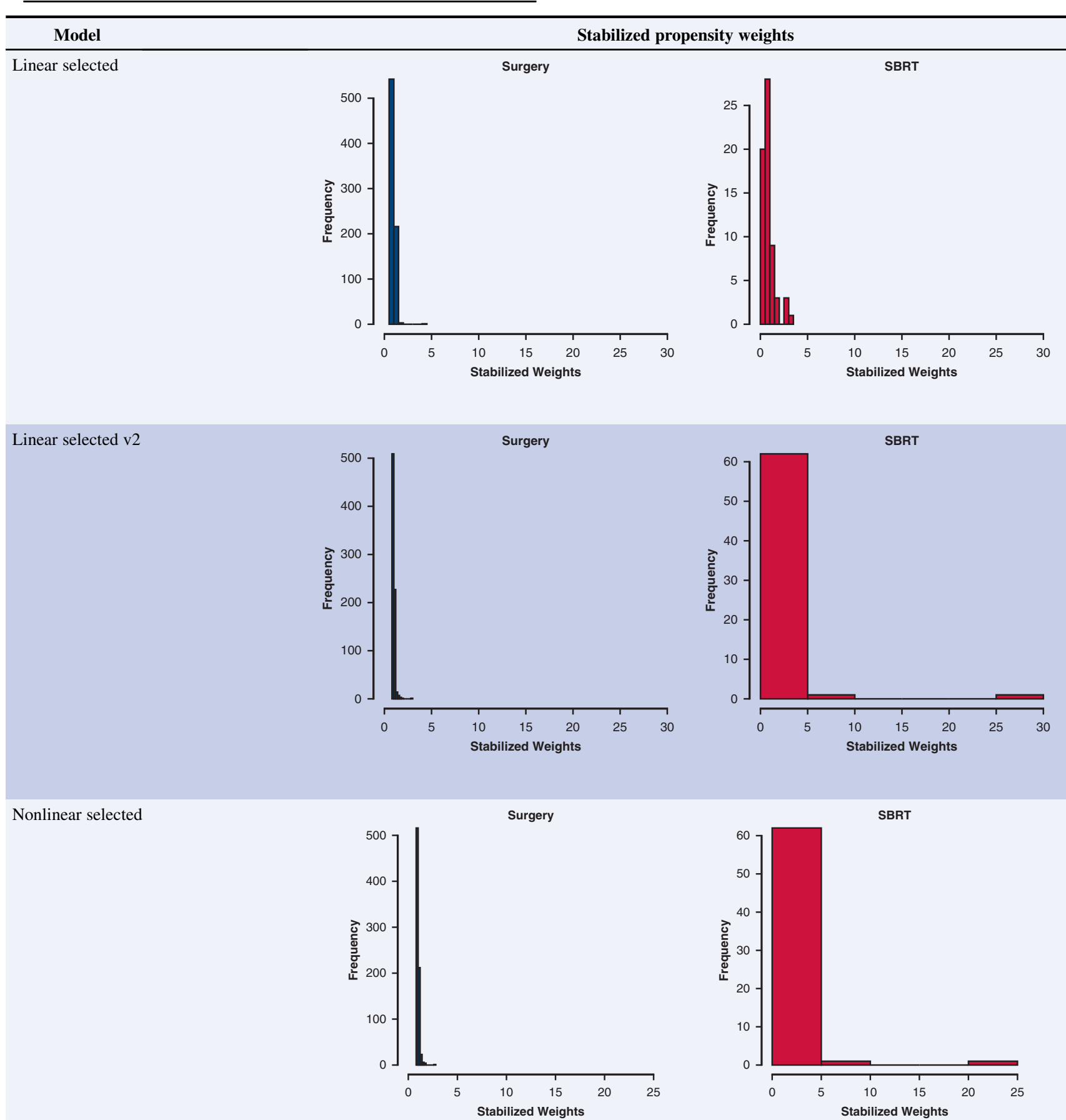


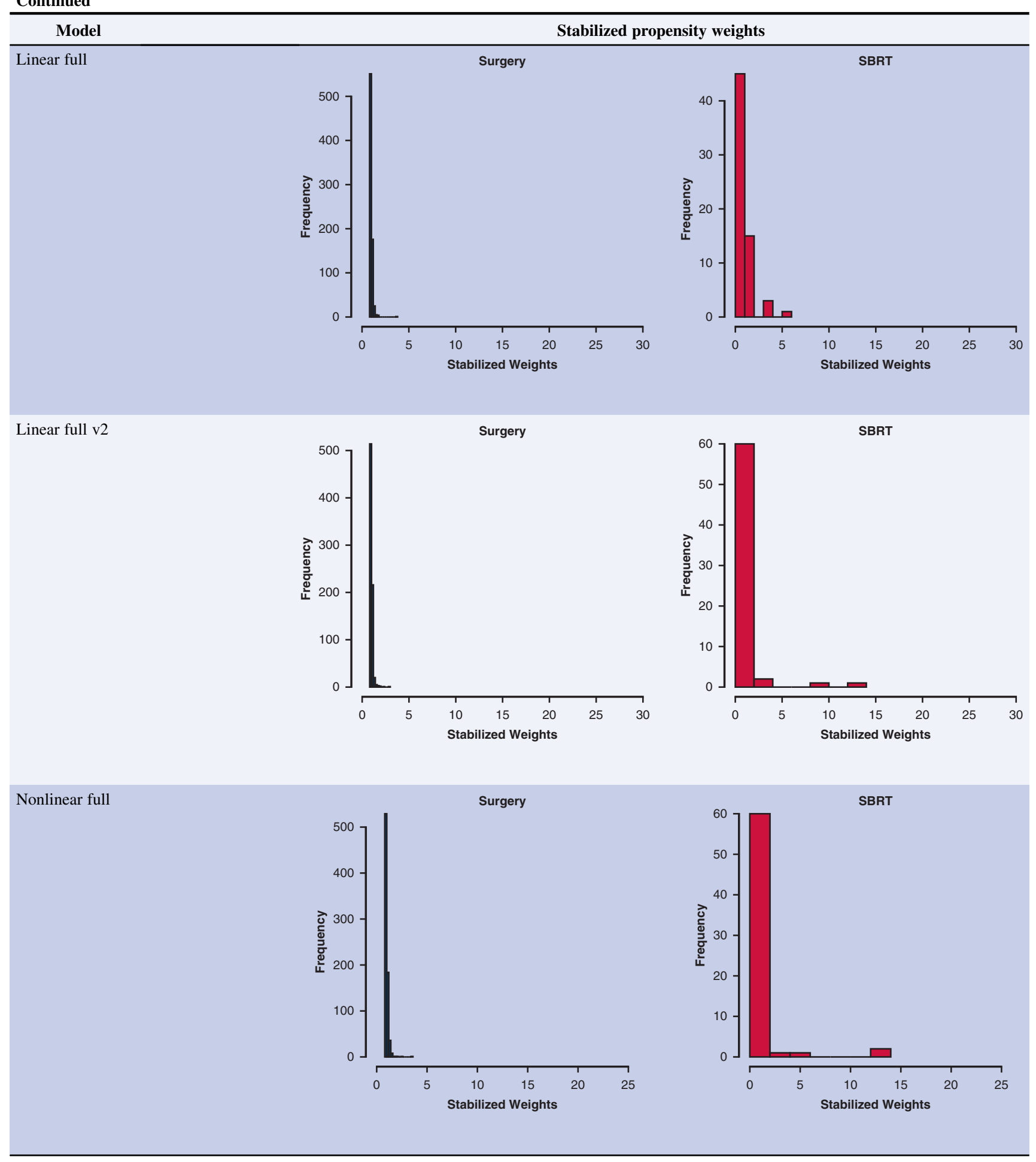

We also examine the distributions of the matching weights in the surgery and SBRT treatment groups, respectively. 


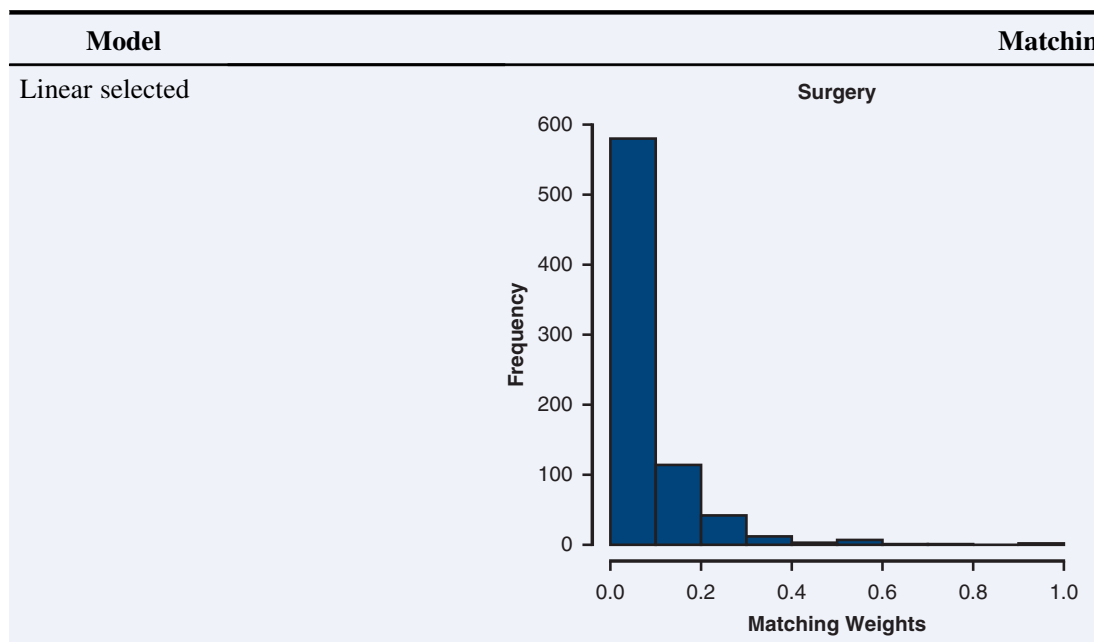

SBRT
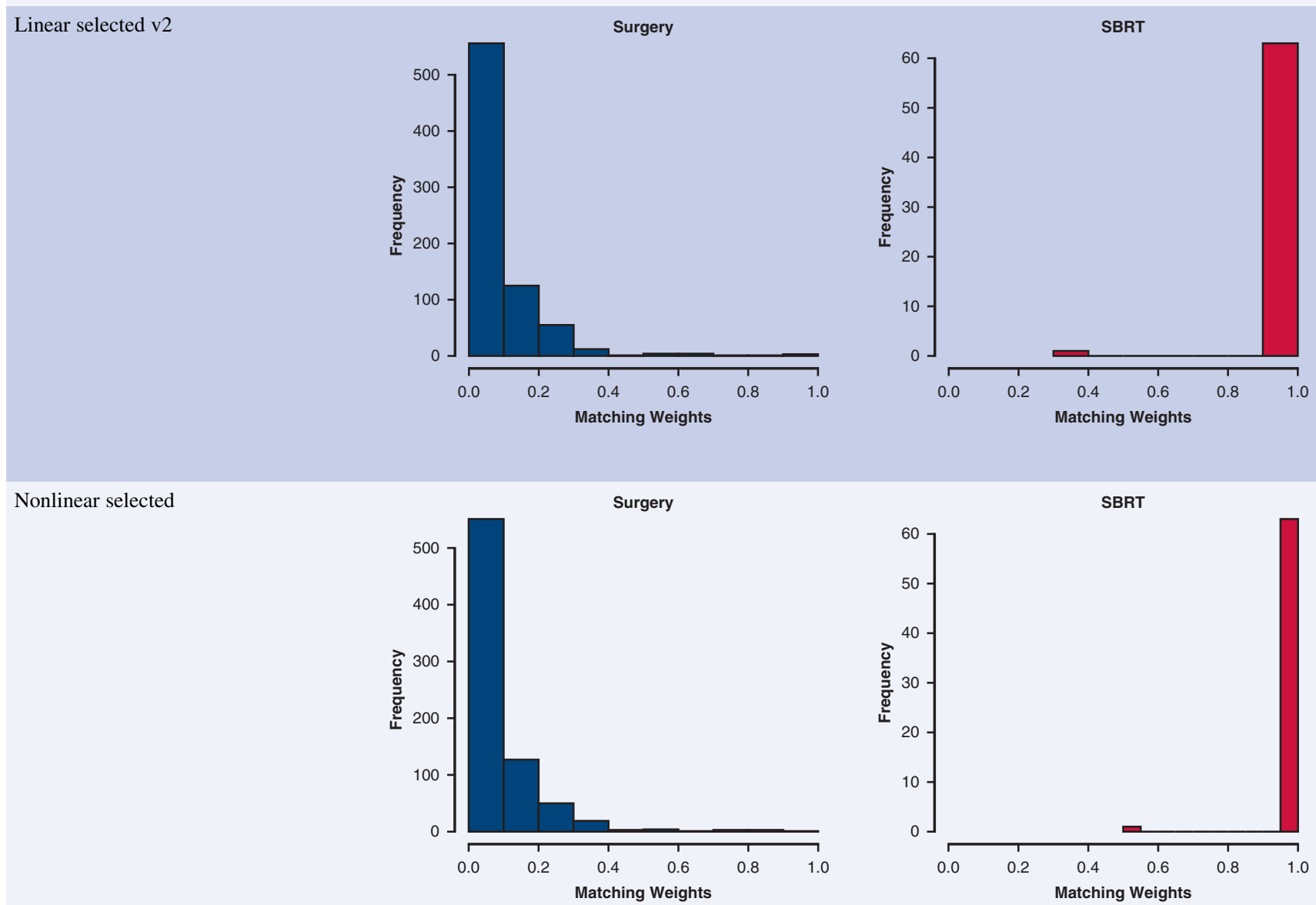

(Continued) 


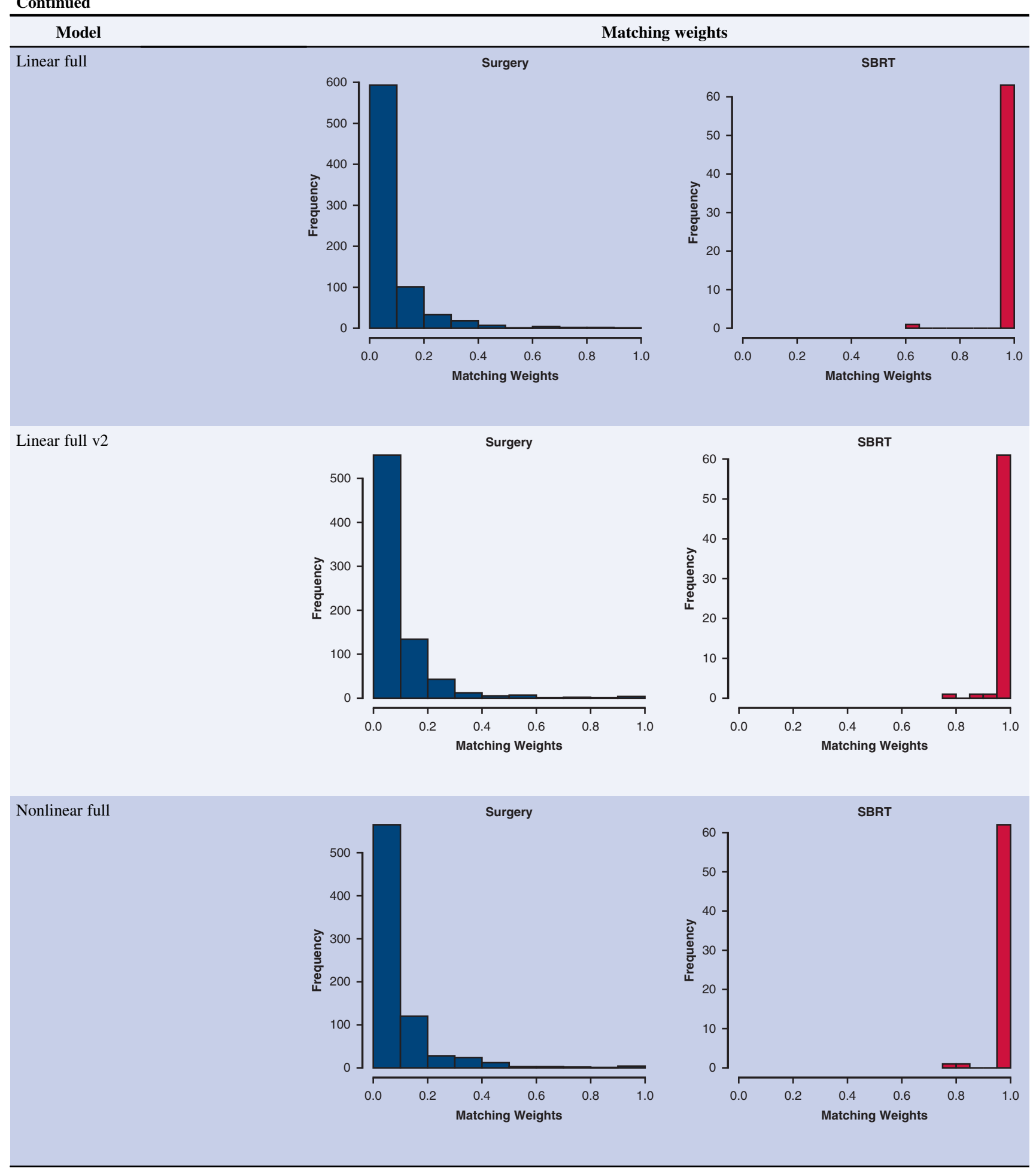




\section{Comparing Balance for Each Weighting Method}

When examining the ASDs, we compare weighted means in continuous variables and weighted percentages in categoric variables.

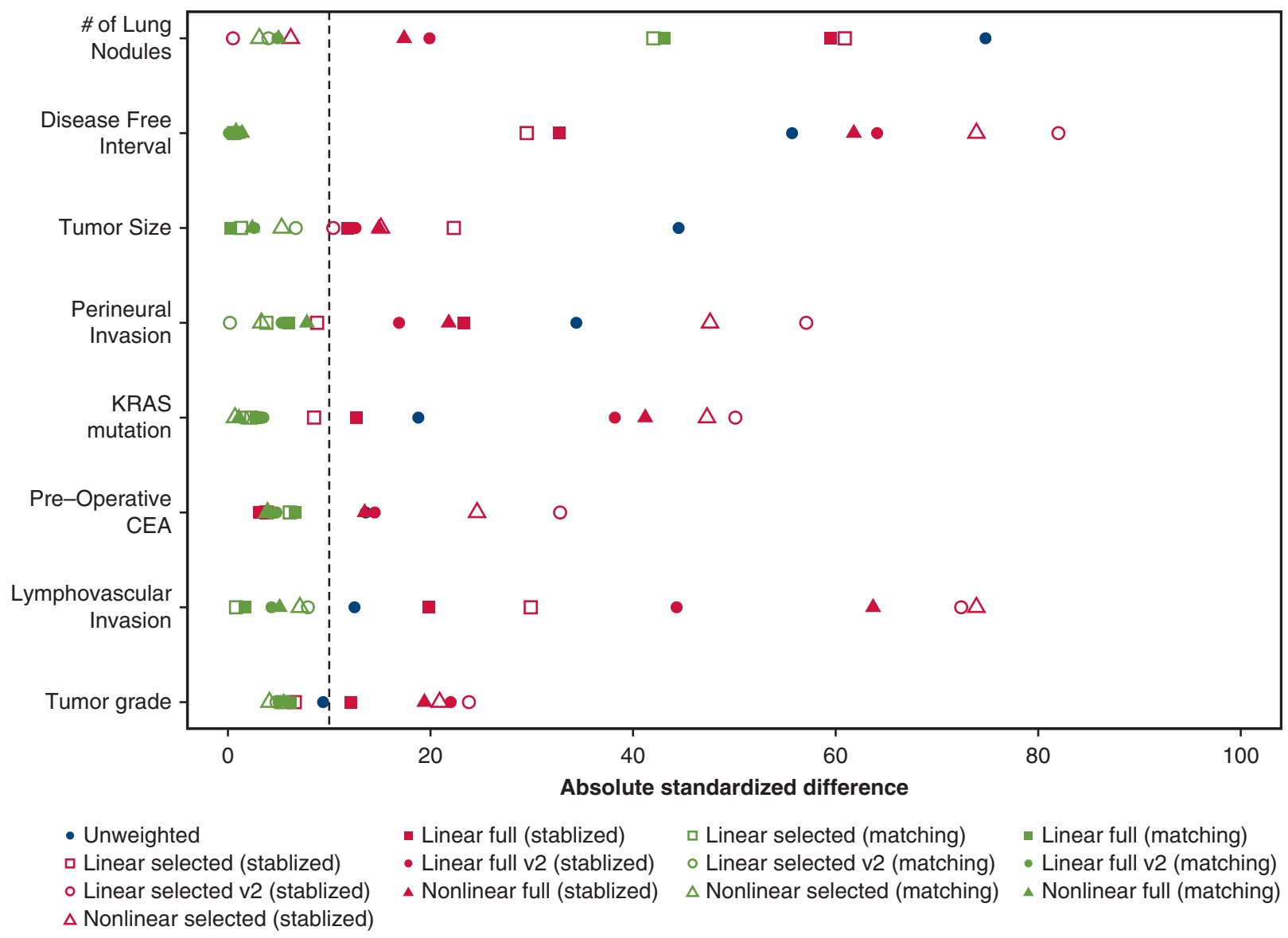


In the following table, we present the absolute standardized difference and highlight those that fall below $10 \%$ using bold text.

\begin{tabular}{|c|c|c|c|c|c|c|c|}
\hline \multirow[b]{2}{*}{ Variables } & \multirow[b]{2}{*}{ Unweighted } & \multicolumn{6}{|c|}{ Stabilized weights } \\
\hline & & Linear selected & Linear selected v2 & Nonlinear selected & Linear full & Linear full v2 & Nonlinear full \\
\hline No. of lung nodules & 74.8 & 60.9 & 0.5 & 6.2 & 59.5 & 19.9 & 17.4 \\
\hline Disease-free interval & 55.7 & 29.5 & 82.0 & 73.9 & 32.7 & 64.1 & 61.8 \\
\hline Tumor size & 44.5 & 22.3 & 10.4 & 15.1 & 11.8 & 12.6 & 14.9 \\
\hline Perineural invasion & 34.4 & 8.8 & 57.1 & 47.6 & 23.3 & 16.9 & 21.8 \\
\hline$K R A S$ mutation & 18.8 & 8.5 & 50.1 & 47.3 & 12.7 & 38.2 & 41.2 \\
\hline Preoperative CEA & 13.6 & 3.8 & 32.8 & 24.6 & 3.1 & 14.5 & 13.5 \\
\hline Lymphovascular invasion & 12.5 & 29.9 & 72.4 & 73.9 & 19.8 & 44.3 & 63.7 \\
\hline Primary tumor grade & 9.4 & 6.6 & 23.8 & 20.9 & 12.1 & 22.0 & 19.4 \\
\hline \multirow[t]{2}{*}{ Maximum ASD } & 74.8 & 60.9 & 82.0 & 73.9 & 59.5 & 64.1 & 63.7 \\
\hline & & \multicolumn{6}{|c|}{ Matching weights } \\
\hline Variables & Unweighted & Linear selected & Linear selected v2 & Nonlinear selected & Linear full & Linear full v2 & Nonlinear full \\
\hline No. of lung nodules & 74.8 & 42.0 & 4.0 & 3.1 & 43.1 & 4.9 & 5.0 \\
\hline Disease-free interval & 55.7 & 0.6 & 0.6 & 0.8 & 0.8 & 0.1 & 1.4 \\
\hline Tumor size & 44.5 & 1.3 & 6.7 & 5.3 & 0.3 & 2.6 & 2.4 \\
\hline Perineural invasion & 34.4 & 3.8 & 0.2 & 3.3 & 6.0 & 5.3 & 7.8 \\
\hline KRAS mutation & 18.8 & 2.3 & 1.5 & 0.7 & 2.8 & 3.5 & 1.1 \\
\hline Preoperative CEA & 13.6 & 6.1 & 4.3 & 3.9 & 6.6 & 4.8 & 3.9 \\
\hline Lymphovascular invasion & 12.5 & 0.8 & 7.9 & 7.1 & 1.7 & 4.3 & 5.1 \\
\hline Primary tumor grade & 9.4 & 5.5 & 4.8 & 4.1 & 6.2 & 5.0 & 5.5 \\
\hline Maximum ASD & 74.8 & 42.0 & 7.9 & 7.1 & 43.1 & 5.3 & 7.8 \\
\hline
\end{tabular}

$C E A$, Carcinoembryonic antigen; $A S D$, absolute standardized difference; $C E A$, carcinoembryonic antigen; $A S D$, absolute standardized difference. 
The weights that achieve good balance $(\max <10 \%)$ in all the prognostically important variables are assessed further: (1) linear selected v2 (matching weight), (2) nonlinear selected (matching weight), (3) linear full v2 (matching weight), and (4) nonlinear full (matching weight)

For these 4 propensity weights, we can also compare the distributions of continuous covariates using side-by-side box plots and empirical CDFs of the number of lung metastases, disease-free interval, tumor size, and preoperative CEA levels.

We also estimate the Kolmogorov-Smirnov test statistic for these continuous covariates. As per the suggestion of Austin and colleagues (2015), we do not use this test statistic for formal hypothesis testing but rather as a quantification of the difference in the distributions of the continuous covariates between the nodules that were treated with SBRT and those that were treated with surgery.

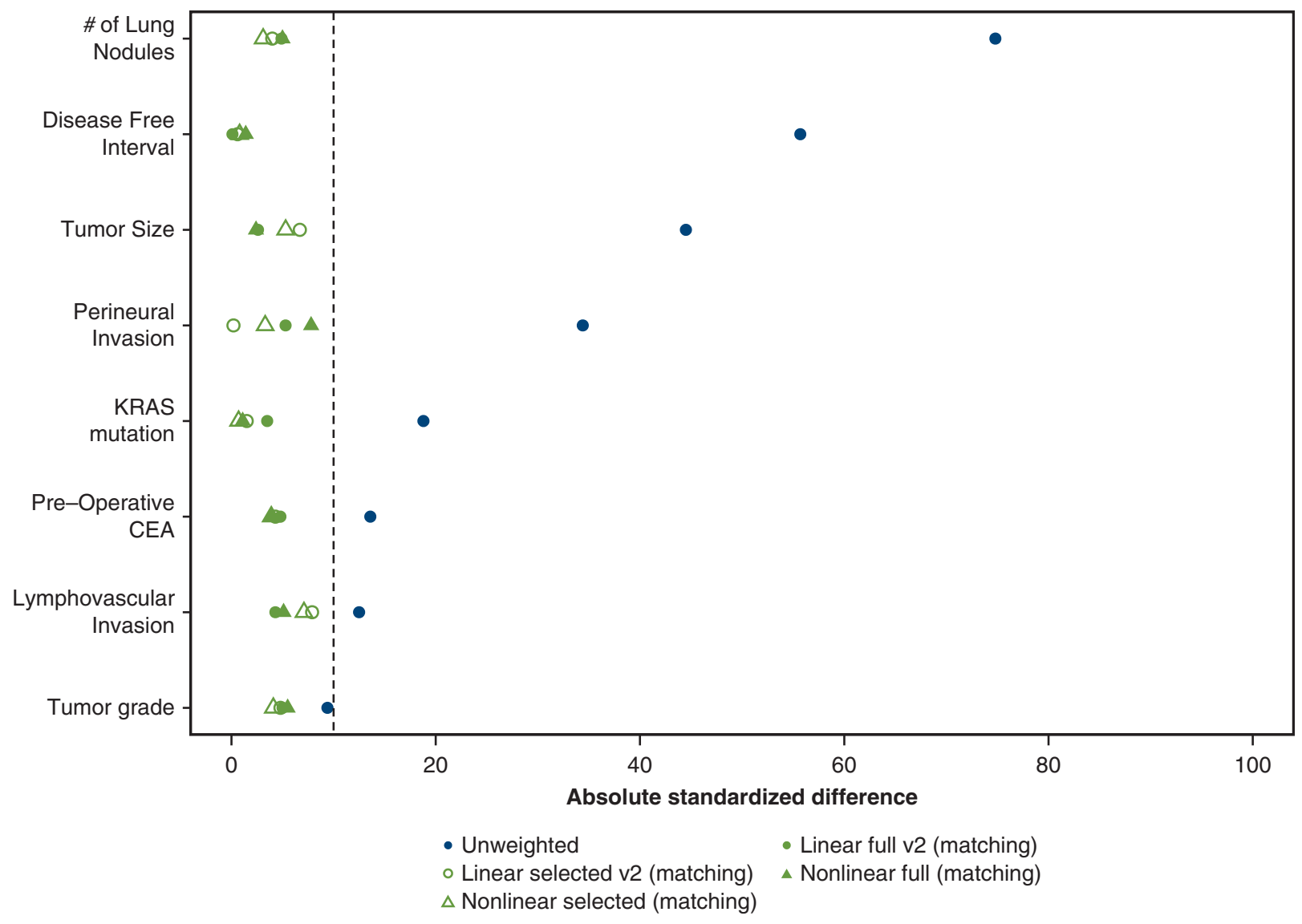



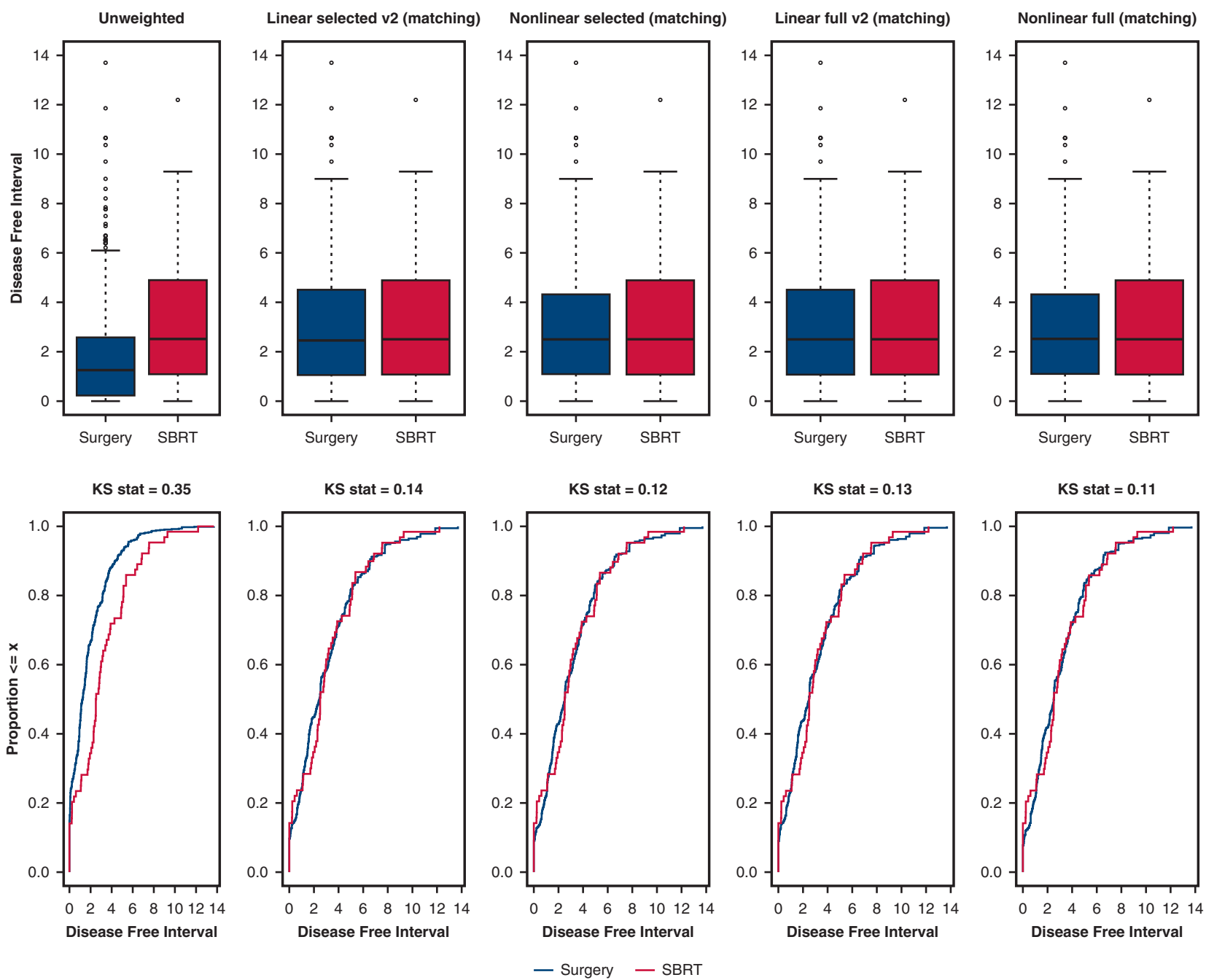

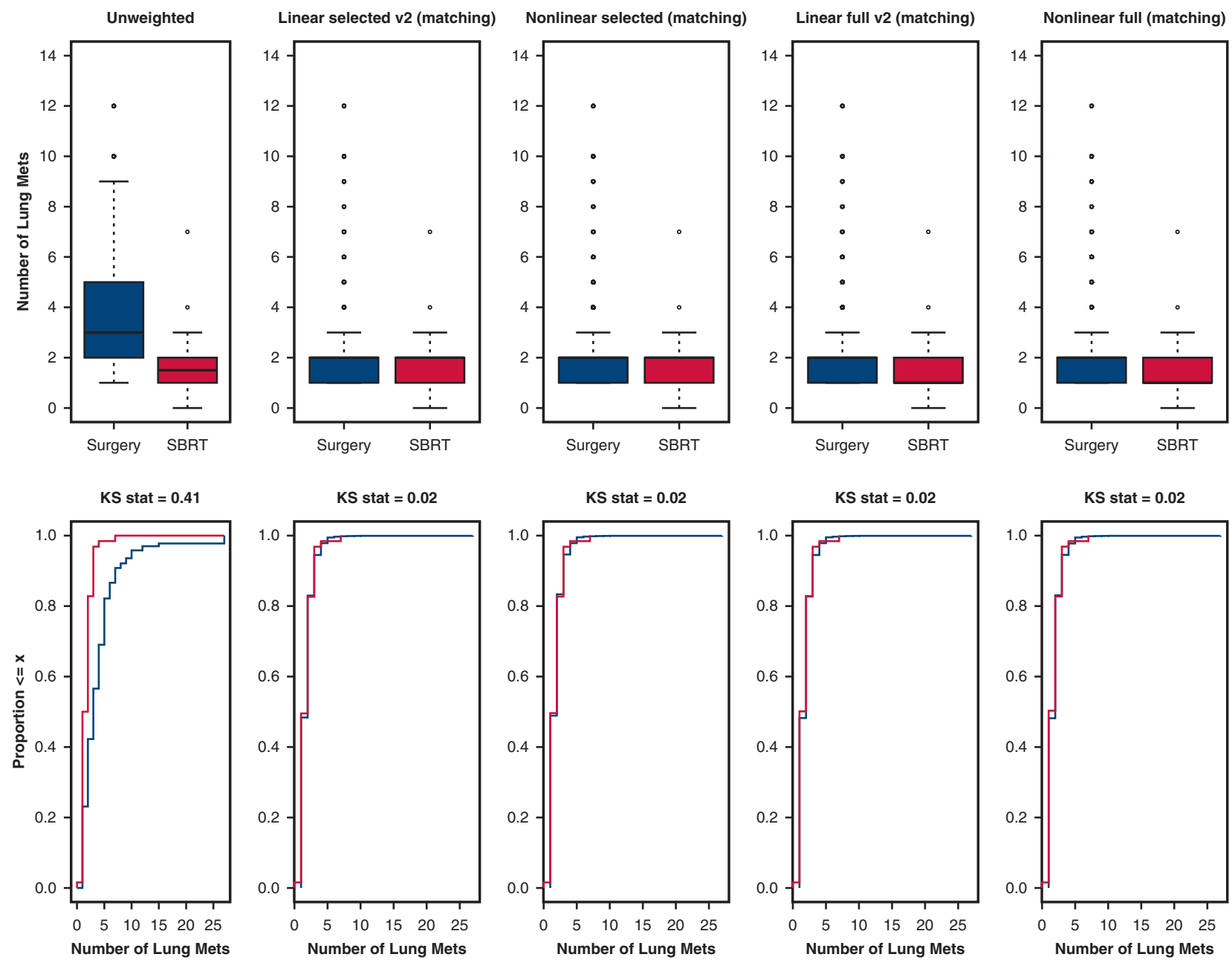

- Surgery - SBRT 

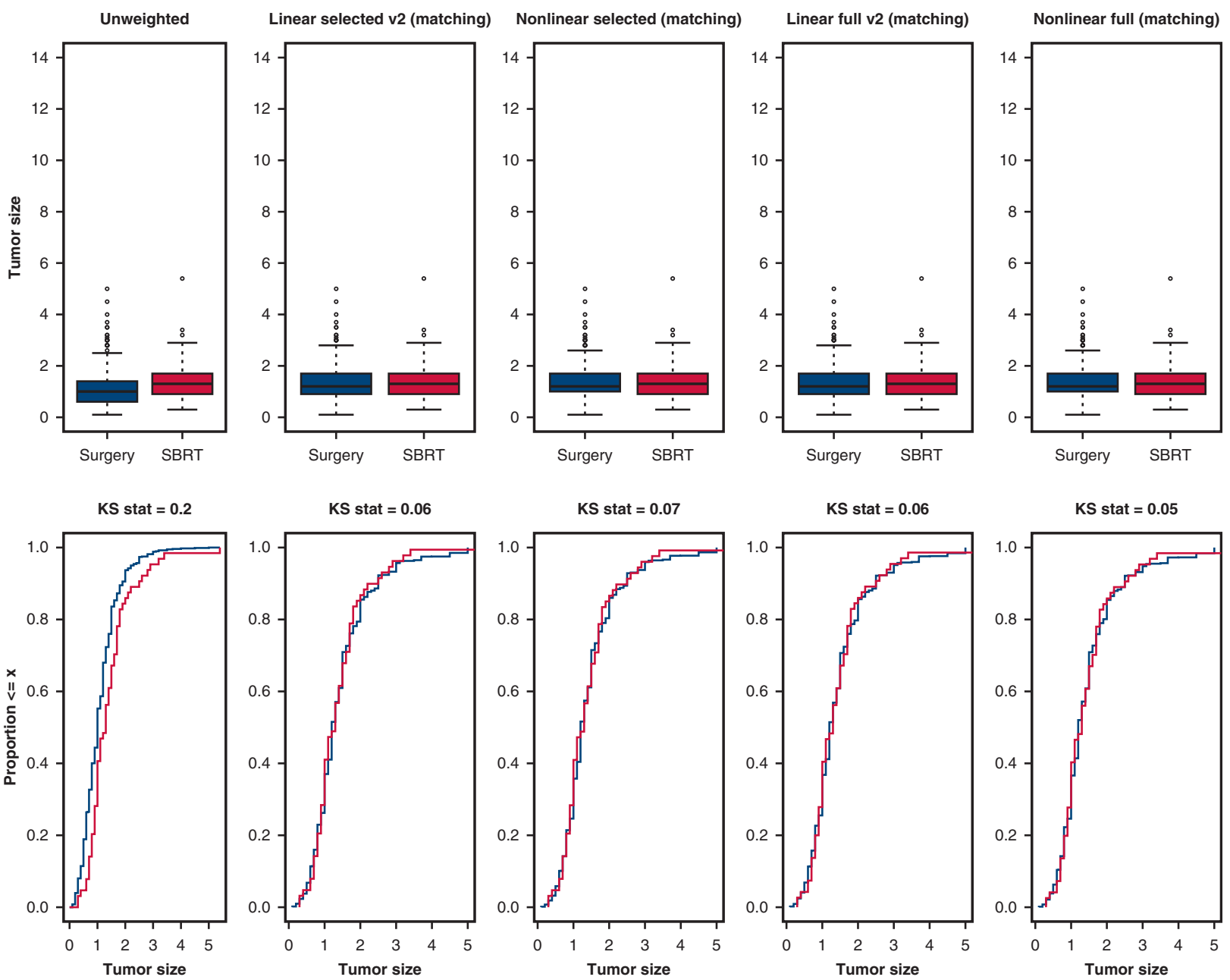

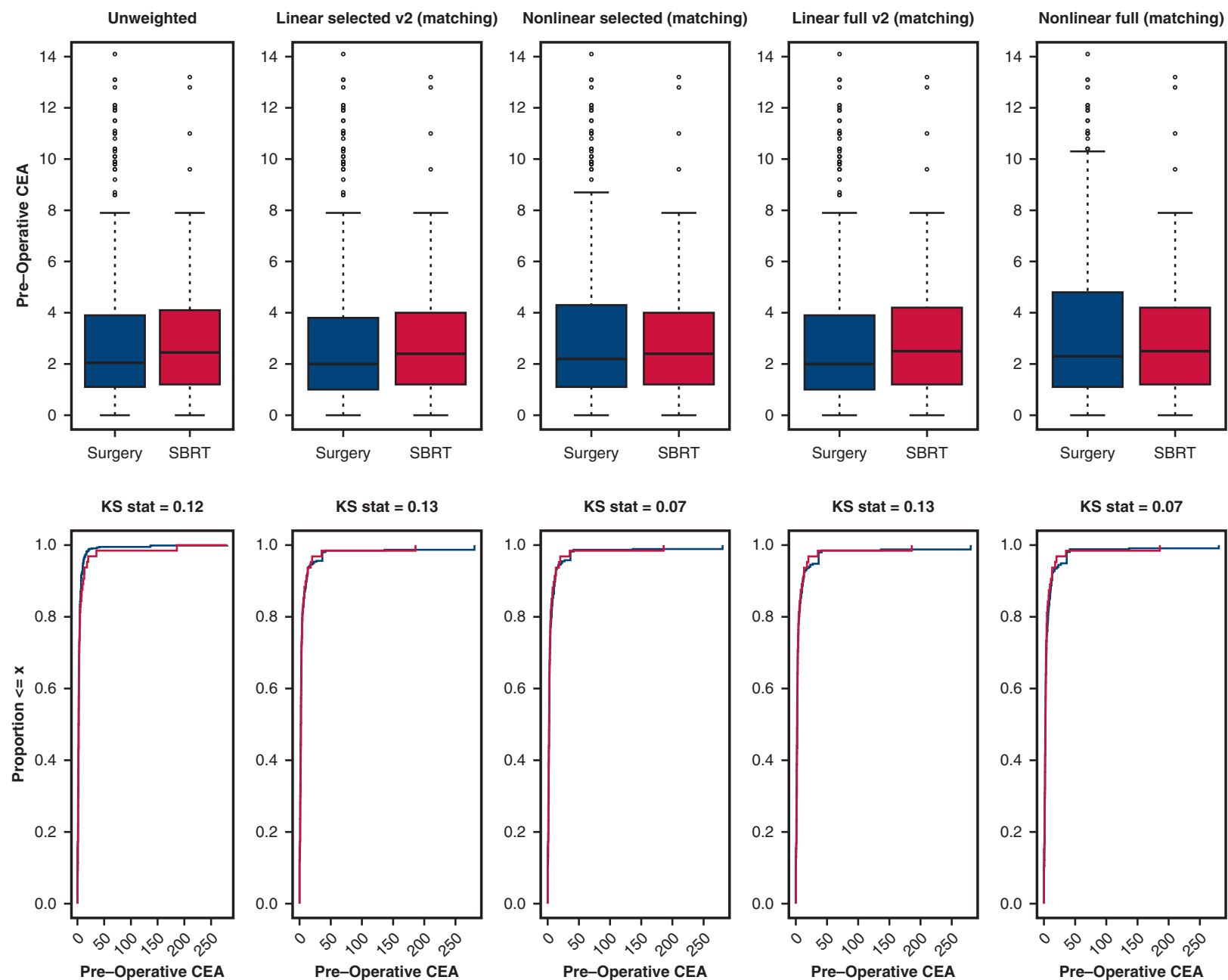

- Surgery - SBRT

Both (2) nonlinear selected (matching weight) and (4) nonlinear full (matching weight) result in distributions of continuous covariates that are similar between the 2 treatment groups and the Kolmogorov-Smirnov test statistics that are identical.

\section{Conclusions}

By taking into account both the absolute standardized differences and the weighted distributions of continuous covariates, we conclude that a nonlinear propensity model with the selected variables and a matching weight achieved the best possible balance between the 2 treatment groups. 


\section{APPENDIX E2. ASSESSING WHETHER DATA IS MISSING COMPLETELY AT RANDOM}

In the tables that follow, we compare outcomes, treatment group, and prognostically important covariates in those with reported and missing covariates at the nodule level. For continuous variables, we report median (interquartile range), and for categoric variables we report $\mathrm{N}(\%)$.

*We used generalized linear models with robust covariance to compare nodules with reported and missing data.

\section{Lymphovascular invasion}

\begin{tabular}{|c|c|c|c|}
\hline Characteristic & Reported $(N=719)$ & Not reported $(N=107)$ & $P$ value* \\
\hline Local recurrence & & & .55 \\
\hline No & $622(87 \%)$ & $90(84 \%)$ & \\
\hline Yes & $97(13 \%)$ & $7(16 \%)$ & \\
\hline Treatment & & & .92 \\
\hline SBRT & $56(8 \%)$ & $8(7 \%)$ & \\
\hline Surgery & $663(92 \%)$ & $99(93 \%)$ & \\
\hline Disease-free interval & $1.27(0.23-2.62)$ & $1.66(0.70-3.52)$ & .09 \\
\hline No. of lung metastases & $3(2-5)$ & $3(1-5)$ & .57 \\
\hline Tumor size & $1.0(0.7-1.4)$ & $1.0(0.6-1.5)$ & .67 \\
\hline Preoperative CEA level & $2.1(1.2-3.9)$ & $2.0(0.9-4.0)$ & .35 \\
\hline Perineural invasion & & & $<.01$ \\
\hline Absent & $209(29 \%)$ & $1(1 \%)$ & \\
\hline Present & $297(41 \%)$ & $2(2 \%)$ & \\
\hline Not reported & $213(30 \%)$ & $104(97 \%)$ & \\
\hline KRAS mutation & & & .28 \\
\hline Absent & $283(39 \%)$ & $45(42 \%)$ & \\
\hline Present & $324(45 \%)$ & $38(36 \%)$ & \\
\hline Not reported & $112(16 \%)$ & $24(22 \%)$ & \\
\hline Primary tumor grade & & & .32 \\
\hline Poorly differentiated & $66(9 \%)$ & $16(15 \%)$ & \\
\hline Moderately differentiated & $647(90 \%)$ & $86(80 \%)$ & \\
\hline Well differentiated & $6(1 \%)$ & $5(5 \%)$ & \\
\hline
\end{tabular}

SBRT, Stereotactic body radiation therapy; $C E A$, carcinoembryonic antigen.

\section{Conclusions}

Those with lymphovascular invasion not reported tend to have lower rates of known perineural invasion present and high rates of unreported perineural invasion. 


\section{KRAS mutation}

\begin{tabular}{|c|c|c|c|}
\hline Characteristic & Reported $(N=690)$ & Not reported $(N=136)$ & $P$ value* \\
\hline Local recurrence & & & $<.01$ \\
\hline No & $580(84 \%)$ & $132(97 \%)$ & \\
\hline Yes & $110(16 \%)$ & $4(3 \%)$ & \\
\hline Treatment & & & .63 \\
\hline SBRT & $52(8 \%)$ & $12(9 \%)$ & \\
\hline Surgery & $638(92 \%)$ & $124(91 \%)$ & \\
\hline Disease-free interval & $1.30(0.23-2.68)$ & $1.47(0.63-3.08)$ & .63 \\
\hline No. of lung metastases & $3(2-5)$ & $2(1-3)$ & $<.01$ \\
\hline Tumor size & $1.0(0.6-1.4)$ & $1.1(0.8-1.5)$ & .50 \\
\hline Preoperative CEA level & $2.1(1.2-4.0)$ & $2.1(1.1-3.5)$ & 63 \\
\hline Perineural invasion & & & $<.01$ \\
\hline Absent & $171(25 \%)$ & $36(29 \%)$ & \\
\hline Present & $273(40 \%)$ & $26(19 \%)$ & \\
\hline Not reported & $246(36 \%)$ & $71(52 \%)$ & \\
\hline Lymphovascular invasion & & & .03 \\
\hline Absent & $158(23 \%)$ & $44(32 \%)$ & \\
\hline Present & $449(65 \%)$ & $68(50 \%)$ & \\
\hline Not reported & $83(12 \%)$ & $24(18 \%)$ & \\
\hline Primary tumor grade & & & .93 \\
\hline Poorly differentiated & $68(10 \%)$ & $14(10 \%)$ & \\
\hline Moderately differentiated & $613(89 \%)$ & $120(88 \%)$ & \\
\hline Well differentiated & $9(1 \%)$ & $2(1 \%)$ & \\
\hline
\end{tabular}

SBRT, Stereotactic body radiation therapy; $C E A$, carcinoembryonic antigen.

\section{Conclusions}

Those with KRAS mutation not reported tend to have low rates of local recurrence, fewer lung metastases, lower rates of known perineural invasion present, and lower rates of known lymphovascular invasion present. 


\section{Perineural invasion}

\begin{tabular}{|c|c|c|c|}
\hline Characteristic & Reported $(N=509)$ & Not reported $(N=317)$ & $P$ value* \\
\hline Local recurrence & & & .90 \\
\hline No & $438(86 \%)$ & $274(86 \%)$ & \\
\hline Yes & $71(14 \%)$ & $43(14 \%)$ & \\
\hline Treatment & & & .55 \\
\hline SBRT & $42(8 \%)$ & $22(7 \%)$ & \\
\hline Surgery & $467(92 \%)$ & $295(93 \%)$ & \\
\hline Disease-free interval & $1.09(0.08-2.37)$ & $1.62(0.86-3.42)$ & $<.01$ \\
\hline No. of lung metastases & $3(2-5)$ & $3(1-5)$ & .27 \\
\hline Tumor size & $1.0(0.6-1.4)$ & $1.0(0.7-1.5)$ & .51 \\
\hline Preoperative CEA level & $2.3(1.4-4.3)$ & $1.6(1.0-2.8)$ & .17 \\
\hline Lymphovascular invasion & & & $<.01$ \\
\hline Absent & $149(29 \%)$ & $53(17 \%)$ & \\
\hline Present & $357(70 \%)$ & $160(50 \%)$ & \\
\hline Not reported & $3(1 \%)$ & $104(33 \%)$ & \\
\hline KRAS mutation & & & .04 \\
\hline Absent & $195(38 \%)$ & $133(42 \%)$ & \\
\hline Present & $249(49 \%)$ & $113(36 \%)$ & \\
\hline Not reported & $65(13 \%)$ & $71(22 \%)$ & \\
\hline Primary tumor grade & & & .36 \\
\hline Poorly differentiated & $44(9 \%)$ & $38(12 \%)$ & \\
\hline Moderately differentiated & $458(90 \%)$ & $275(87 \%)$ & \\
\hline Well differentiated & $7(1 \%)$ & $4(1 \%)$ & \\
\hline
\end{tabular}

SBRT, Stereotactic body radiation therapy; $C E A$, carcinoembryonic antigen.

\section{Conclusions}

Patients with perineural invasion not reported tend to have longer disease-free intervals, lower rates of known lymphovascular invasion present, and lower rates of known KRAS mutations present. 


\section{Preoperative CEA level}

\begin{tabular}{|c|c|c|c|}
\hline Characteristic & Reported $(N=806)$ & Not reported $(\mathrm{N}=20)$ & $P$ value* \\
\hline Local recurrence & & & .64 \\
\hline No & $694(86 \%)$ & $18(90 \%)$ & \\
\hline Yes & $112(14 \%)$ & $2(10 \%)$ & \\
\hline Treatment & & & .03 \\
\hline SBRT & $59(7 \%)$ & $5(25 \%)$ & \\
\hline Surgery & $747(93 \%)$ & $15(75 \%)$ & \\
\hline Disease-free interval & $1.30(0.23-2.68)$ & $4.26(0.29-5.42)$ & .15 \\
\hline No. of lung metastases & $3(1-5)$ & $2(1.8-6.0)$ & .58 \\
\hline Tumor size & $1.0(0.6-1.4)$ & $1.0(1.8-6.0)$ & .70 \\
\hline Perineural invasion & & & .94 \\
\hline Absent & $204(25 \%)$ & $6(30 \%)$ & \\
\hline Present & $292(36 \%)$ & $7(35 \%)$ & \\
\hline Not reported & $310(38 \%)$ & $7(35 \%)$ & \\
\hline Lymphovascular invasion & & & .18 \\
\hline Absent & $193(24 \%)$ & $9(45 \%)$ & \\
\hline Present & $509(63 \%)$ & $8(40 \%)$ & \\
\hline Not reported & $104(13 \%)$ & $3(15 \%)$ & \\
\hline KRAS mutation & & & .61 \\
\hline Absent & $319(40 \%)$ & $9(45 \%)$ & \\
\hline Present & $355(44 \%)$ & $7(35 \%)$ & \\
\hline Not reported & $132(16 \%)$ & $4(20 \%)$ & \\
\hline Primary tumor grade & & & .48 \\
\hline Poorly differentiated & $81(10 \%)$ & $1(5 \%)$ & \\
\hline Moderately differentiated & $714(89 \%)$ & $95(19 \%)$ & \\
\hline Well differentiated & $11(1 \%)$ & $0(0 \%)$ & \\
\hline
\end{tabular}

$S B R T$, Stereotactic body radiation therapy

\section{Conclusions}

Patient with no reported preoperative CEA levels had higher rates of receiving SBRT. 